\title{
Prevalence of disability and associated factors in Dabat Health and Demographic Surveillance System site, northwest Ethiopia
}

\author{
Mulugeta Bayisa Chala ${ }^{1 *}$, Solomon Mekonnen ${ }^{2,6}$, Gashaw Andargie ${ }^{3,6}$, Yigzaw Kebede ${ }^{4,6}$, Mezgebu Yitayal ${ }^{3,6}$, \\ Kassahun Alemu ${ }^{4,6}$, Tadesse Awoke ${ }^{4,6}$, Mamo Wubeshet ${ }^{5,6}$, Temesgen Azmeraw ${ }^{6}$, Melkamu Birku ${ }^{6}$, Amare Tariku² $^{2}$ \\ Abebaw Gebeyehu', Alemayehu Shimeka ${ }^{3}$ and Zemichael Gizaw ${ }^{5}$
}

\begin{abstract}
Background: Despite the high burden of disability in Ethiopia, little is known about it, particularly in the study area. Hence, this study aimed to investigate the prevalence and factors associated with disability at Dabat Health and Demographic Surveillance System (HDSS) site, northwest Ethiopia.

Method: A population-based study was conducted from October to December 2014 at Dabat HDSS site. A total of 67,395 people were included in the study. The multivariable binary logistic regression analysis was employed to identify factors associated with disability. The Adjusted Odds Ratio (AOR) with a 95\% Confidence Interval (CI) was estimated to show the strength of association. A $p$-value of $<0.05$ was used to declare statistical significance.

Results: One thousand two hundred twenty-eight individuals were reported to have a disability giving a prevalence rate of $1.82 \%$, of which, about $39 \%$ was related to a vision disability. The high odds of disability were observed among the elderly ( $\geq 50$ years) [AOR: 4.49; 95\% Cl: 1.95, 10.33], severely food in-secured [AOR: $2.11 ; 95 \%$ Cl: 1.59, 2.80], and separated marital status [AOR: $7.52 ; 95 \% \mathrm{Cl}: 1.18,47.84]$. While having a paid job [AOR: $0.46 ; 95 \% \mathrm{Cl}: 0.28,0.77$ ], being in the richest quintile [AOR: $0.55 ; 95 \% \mathrm{Cl}: 0.41,0.75]$, and high engagement in work-related physical activities [AOR: 0.36; $95 \%$ Cl: $0.27,0.49$ ] were inversely associated with the disability.
\end{abstract}

Conclusion: Disability is a major public health problem, and the burden is noticeable in the study area. Vision disability is the highest of all disabilities. Thus, efforts must be made on educating the public about disability and injury prevention. Measures that reduce disability should target the elderly, the poorer and the unemployed segment of the population.

Keywords: Disability, Vision disability, HDSS, Dabat, Ethiopia

\section{Background}

The World Health Organization estimates that globally around 1 billion people (15\%) live with some sort of disability [1]; the majority live in resource-limited settings $[2,3]$. This number is increasing due to the rise of an aging population, advancement of medical care, and population growth across the world [3]. However, the subject is considered as a human right and global health issues as well as an agenda for development [2].

\footnotetext{
* Correspondence: muluphysio@yahoo.com

${ }^{1}$ Department of Physiotherapy, School of Medicine, College of Medicine and Health Science, University of Gondar, P.o. Box 196, Gondar, Ethiopia

Full list of author information is available at the end of the article
}

Disability is defined as having difficulties with performing activities of daily living (ADL), and the phenomena are expressed as an interaction between an individual's health condition and the environment he or she is living in $[4,5]$. The Washington group defined disability as having at least a severe difficulty or limitation in performing key ADL, such as sight, hearing, walking or climbing steps, remembering, or concentrating [6].

People with disability face different challenges during their lifetime. This can be explained by social exclusion, stigma, severe health challenges, limited access to school and business [4]. In addition, it affects not only the person's individual life but also his or her participation and role in society [2]. The difficulties and barriers 
experienced by people with disabilities are not only due to their own health conditions, but also because of inadequate policies and standards empowering and supporting these people. This is usually reflected in negative attitudes towards them, prejudices, and the inaccessibility of services [2]. In fact, disability is also linked with poverty $[5,7,8]$, and people living with disabilities in developing countries face many challenges in their daily life.

Disability is caused by several factors, such as poor living conditions, poor nutrition, lack of health and sanitation facilities, different forms of accidents and injuries [7], congenital malformation, psychological dysfunctions, and birth related incidents [9].

In order to create equal opportunities in every sphere of their life, many countries, including Ethiopia, signed the convention of the rights of people with disabilities ratified by the United Nations in 2006 [2]. However, there is a major gap between implementing the stated convention and the day to day life of people with a disability. Besides, the convention urges the member countries to establish a proper mechanism that ensures a regular collection of data at the population level [10].

Ethiopia has also signed the African Decades of Disabled Persons (SADPD), which was established in South Africa in 2004 with the responsibility of coordinating efforts and resources on disability programs in Africa [7]. However, in lower and middle-income countries, such as Ethiopia, information on specific interventions, service utilization, and legislation is lacking [11]. In addition, there are only a small number of inaccessible rehabilitation facilities in the country. Besides, the lack of accessibility and employment opportunities are noted in almost all of the service areas [7], making it very challenging for people with disabilities to get out of the povertydisability cycle. Despite the high burden, and interwoven challenges, little is known about disability in Ethiopia, particularly in the study area. This is believed to impose a great challenge for policy makers and planners to include people with disability in the inclusive development. Hence, the aim of this study was to assess the self-reported prevalence and factors associated with disability at the Dabat HDSS site.

\section{Methods}

\section{Study design and setting}

The study was conducted at the Dabat HDSS site where the census is conducted every 7 years in order to assess the changes in vital events, demography (living conditions, economic status, and health) of the population. The detailed activities of the HDSS site are mentioned elsewhere [12].This study is part of the re-census conducted from October to December 2014.

The Dabat HDSS site is located in Dabat District, northwest Ethiopia. The site was established in 1996. It covers a total of 13 kebeles, smallest administrative unit in Ethiopia, (9 rural and 4 urban) with 16,053 households and 67,395 inhabitants. The kebeles in the surveillance site were selected randomly, by taking all ecological zones (high land, middle land, and lowland) into account. Every household in the selected kebeles were targeted during the data collection period. Dabat HDSS is a full member of the International Network of Demographic Evaluation of Populations and Their Health (INDEPTH), a network of 44 HDSSs from the Global South.

\section{Study population and data collection}

All permanent residents in the Dabat HDSS site were included in the study. The heads of each household were interviewed to collect the necessary information with regard to events that happened in the family. When a member of a family was found to have any form of disability, he or she was interviewed by trained, diploma graduate data collectors working in the research site using a structured and pretested questionnaire. The study utilized the re-census data.

Disability, the outcome variable, was defined according to the 2011 Labor Force Survey ad hoc module (LFS AHM) [13]. Hence, the status of disability is ascertained if a person has difficulty in carrying out any of the basic activities of hearing, seeing, walking, self-care, and cognition as parts of activities of daily living. A binary outcome of "yes" or "no" option was given to identify the presence or absence of disability. For example, a respondent would answer "yes" if he or she had difficulty in self-care, and "no" if there is no problem at all. Different independent variables (Table 1) were used to assess if there was an association with our outcome variable.

Food Security is defined as existing when "all people, at all times, have physical and economic access to sufficient, safe, and nutritious food to meet their dietary needs and food preferences for an active and healthy life". In order to assess the Food security status of households, an 18 item community food insecurity accessible scale assessment tool was adapted from Household Food Insecurity Access Scale (HFIAS): Indicator Guide VERSION 3 and categorized into four levels using HFIS variables [14]. If the respondent answers "yes" to an occurrence question, a frequency of occurrence question was asked to determine whether the condition happened rarely (once or twice), sometimes (three to ten times) or often (more than ten times) in the past 4 weeks (food secure, mildly food insecure, moderately food insecure, severely food insecure). This scale has already been validated in Ethiopia [15].

The household wealth index was computed for urban and rural residents separately using the Principal Component Analysis (PCA). The urban wealth status was 
Table 1 Socio-demographic characteristics of the population of Dabat HDSS, northwest Ethiopia, October-December 2014 $(N=67,395)$

\begin{tabular}{|c|c|c|}
\hline Variables & Frequency & Percent \\
\hline \multicolumn{3}{|l|}{ Sex } \\
\hline $\begin{array}{l}\text { Male } \\
\text { Female }\end{array}$ & $\begin{array}{l}33,181 \\
34,214\end{array}$ & $\begin{array}{l}49.23 \\
50.77\end{array}$ \\
\hline \multicolumn{3}{|l|}{ Age in years } \\
\hline $\begin{array}{l}\leq 14 \\
15 \text { to } 49 \\
\geq 50\end{array}$ & $\begin{array}{l}28,956 \\
29,807 \\
8630\end{array}$ & $\begin{array}{l}42.97 \\
44.23 \\
12.81\end{array}$ \\
\hline \multicolumn{3}{|l|}{ Residence } \\
\hline $\begin{array}{l}\text { Rural } \\
\text { Urban }\end{array}$ & $\begin{array}{l}50,769 \\
16,835\end{array}$ & $\begin{array}{l}75.10 \\
24.9\end{array}$ \\
\hline \multicolumn{3}{|l|}{ Marital status } \\
\hline $\begin{array}{l}\text { Under } 10 \text { years old } \\
\text { Married } \\
\text { Single } \\
\text { Divorced } \\
\text { Widowed } \\
\text { Separated } \\
\text { Cohabiting }\end{array}$ & $\begin{array}{l}20,089 \\
21,814 \\
19,746 \\
2390 \\
2369 \\
917 \\
68\end{array}$ & $\begin{array}{l}29.81 \\
32.37 \\
29.30 \\
3.55 \\
3.52 \\
1.36 \\
0.10\end{array}$ \\
\hline \multicolumn{3}{|l|}{ Religion } \\
\hline $\begin{array}{l}\text { Orthodox } \\
\text { Muslim } \\
\text { Others }^{a}\end{array}$ & $\begin{array}{l}64,940 \\
2444 \\
11\end{array}$ & $\begin{array}{l}96.36 \\
3.63 \\
0.01\end{array}$ \\
\hline \multicolumn{3}{|l|}{ Ethnicity } \\
\hline $\begin{array}{l}\text { Amhara } \\
\text { Tigre } \\
\text { Others }\end{array}$ & $\begin{array}{l}67,294 \\
84 \\
17\end{array}$ & $\begin{array}{l}99.85 \\
0.12 \\
0.02\end{array}$ \\
\hline \multicolumn{3}{|l|}{ Education } \\
\hline $\begin{array}{l}\text { Not on education ( }<7 \text { years) } \\
\text { Unable to read and write } \\
\text { Read and write } \\
\text { Grade } 1-4 \\
\text { Grade } 5-6 \\
\text { Grade } 7-8 \\
\text { Grade } 9-10 \\
\text { Grade } 11-12 \\
\text { Grade } 12 \text { and above }\end{array}$ & $\begin{array}{l}13,672 \\
21,149 \\
5541 \\
10,960 \\
4560 \\
3590 \\
4375 \\
1957 \\
1591\end{array}$ & $\begin{array}{l}20.29 \\
31.38 \\
8.22 \\
16.26 \\
6.77 \\
5.33 \\
6.49 \\
2.90 \\
2.36\end{array}$ \\
\hline \multicolumn{3}{|l|}{ Doing work related physical activity } \\
\hline $\begin{array}{l}\text { Never } \\
\text { Sometimes } \\
\text { Most of the time }\end{array}$ & $\begin{array}{l}4498 \\
16,414 \\
16,872\end{array}$ & $\begin{array}{l}12.00 \\
43.00 \\
45.00\end{array}$ \\
\hline \multicolumn{3}{|l|}{ Occupation } \\
\hline $\begin{array}{l}\text { No occupation(under } 10 \text { years) } \\
\text { Students } \\
\text { Farmers } \\
\text { Employed permanent } \\
\text { Private job } \\
\text { Job seeker } \\
\text { Merchant } \\
\text { House maid } \\
\text { Employed contract } \\
\text { Retired } \\
\text { Others(housewife, shepherd, disabled) }\end{array}$ & $\begin{array}{l}20,436 \\
13,955 \\
12,647 \\
1951 \\
1167 \\
1056 \\
656 \\
623 \\
328 \\
296 \\
33\end{array}$ & $\begin{array}{l}38.45 \\
26.26 \\
23.80 \\
3.67 \\
2.20 \\
1.99 \\
1.23 \\
1.17 \\
0.62 \\
0.56 \\
0.05\end{array}$ \\
\hline \multicolumn{3}{|l|}{ Location } \\
\hline $\begin{array}{l}\text { Low land } \\
\text { High land }\end{array}$ & $\begin{array}{l}22,380 \\
45,015\end{array}$ & $\begin{array}{l}33.2 \\
66.8\end{array}$ \\
\hline
\end{tabular}

Table 1 Socio-demographic characteristics of the population of Dabat HDSS, northwest Ethiopia, October-December 2014 $(N=67,395)$ (Continued)

\begin{tabular}{lll}
\hline Relation to the HH head & & \\
HH head & 16,082 & 23.86 \\
Housewife & 10,542 & 15.64 \\
Son/daughter & 34,702 & 51.49 \\
Sister/brother & 538 & 0.80 \\
Mother/father & 310 & 0.46 \\
Grandson/granddaughter & 3095 & 4.59 \\
Other relative & 1196 & 1.77 \\
Other non-relative & 930 & 1.38 \\
Family size & & \\
1-4 & 24,512 & 36.35 \\
5-9 & 41,667 & 61.79 \\
10-15 & 1250 & 1.85 \\
Wealth status & & \\
$\quad$ Poorest quintile & & \\
Second quintile & 9475 & 14.58 \\
Third quintile & 11,344 & 17.45 \\
$\quad$ Fourth quintile & 13,031 & 20.05 \\
Richest Quintile & 14,593 & 22.45 \\
\hline a Catholic and Protestant & 16,577 & 25.47 \\
b Oromo and Agaw \\
HH stands for Household
\end{tabular}

calculated by considering properties, like selecting household assets, while the only tropical livestock unit was used for the rural residents. The variables were initially screened using the commonality value. In the PCA, the Eigenvalue of greater than one, the KMO distribution, and in the final model, the common factor scores were summed and ranked in Poorest quintile, Second quintile, Third quintile, Fourth quintile, and Richest Quintile [16].

\section{Data processing and analysis}

Data was entered into the Household Registration System (HRS) version 2.1 and analyzed using STATA version 14. Binary logistic regression was fitted to elicit factors associated with disability. The bivariable analysis was carried out, and variables with $p$-values of $<0.2$ were fitted to the multivariable logistic regression analysis. Both the crude odds ratio (COR) and the adjusted odds ratio (AOR) with the corresponding 95\% Confidence Interval (CI) were used to show the strength of association. Finally, a p-value of $<0.05$ was used to declare statistical significance.

\section{Results}

A population of 67,395 living in 16, 039 households were included in the study. About 34,214 (50.77\%) respondents were female and 50,769 (75.1\%) were rural dwellers. The mean age of the study subjects was 23.1 years (SD 19.1 years). Nearly half, 28,952 (42.96\%), of the participants were under 15 years of age (Table 1 ). 
In this community, 1228 people were found with disabilities which corresponds to the overall prevalence rate of $1.82 \%$ [95\%CI, 1.72, 1.92]. The mean $( \pm \mathrm{SD})$ age of people with disabilities was $44.36( \pm 23.2)$ years. Regarding the types of disability, more than one-third, 534 (39\%), were related to vision disability, followed by hearing 244 (18\%) and walking 230 (17\%) disabilities (Fig. 1). Moreover, cognitive and self-care disabilities account for $210(15 \%)$ and $112(11 \%)$, respectively, for the total disability. Among 1228 people who reported a disability, $11.5 \%$ of them have reported two or more types of disabilities.

Fall down injury and penetration by animal horn accounted for 155 (35.9\%) and 88 (20.4\%), respectively, of the common causes of disability (Table 2). Of the total study participants who experienced injury, 155 (35.9\%) did not seek any treatment, while 85 (19.7\%) went to traditional healers and 85 (19.7\%) obtained some sort of treatment at home (Table 2). Regardless of gender, the proportion of vision disability increased with increasing age, while the rest of the disabilities were prevalent among the working age group (15-49 years old). One thousand three hundred sixty nine number of disabilities (20.3 cases per 1000 population) types of disabilities were reported among Dabat HDSS (Table 3).

The result of the multivariable logistic regression analysis showed that age, food security status, marital status, occupation, wealth status, and work-related physical activities were significantly and independently associated with disability. Consequently, the odds of getting disability were 4.49 times higher among elderly ( $\geq 50$ years) population, compared to the younger ones ( $\leq 14$ years) $[\mathrm{AOR}=4.49 ; 95 \%$ CI: 1.95, 10.33]. The likelihood of disability was high among respondents with separated
Table 2 Causes of injury and post-injury health seeking behaviour among Dabat HDSS, North West Ethiopia, October-December $2014(N=432)$

\begin{tabular}{lll}
\hline Variable & Frequency & Percentage \\
\hline Causes of injury & 155 & 35.9 \\
Fall & 13 & 3.00 \\
Burn & 8 & 1.85 \\
Poisoning & 1 & 0.23 \\
Drowning & 12 & 2.77 \\
Car accident & 57 & 13.12 \\
Sharp objects & 9 & 2.08 \\
Farming equipment & 55 & 12.73 \\
Hit by other person by stick & 34 & 7.87 \\
Animal Bite & 88 & 20.4 \\
Penetration by animals & $432)$ & \\
Post injury health seeking behavior $(\mathrm{N}$ & 155 & 35.9 \\
Did not need help & 85 & 19.6 \\
Treatment at home & 17 & 3.9 \\
Health post & 7 & 1.62 \\
Clinic & 57 & 13.2 \\
Health center & 26 & 6.02 \\
Hospital & 85 & 19.7 \\
Traditional Healer & & \\
\hline
\end{tabular}

marital status $[\mathrm{AOR}=7.52 ; 95 \% \mathrm{CI}: 1.18,47.84]$ and food in- secured households [AOR: 2.11; 95\% CI: 1.59 , 2.80]. However, being engaged in paid jobs was noted with lower odds of disability [AOR $=0.46$; $95 \%$ CI: 0.28 , 0.77 ] as compared to their counterparts. Similarly, respondents from a household with the highest wealth status [AOR: 0.76; 95\% CI: 0.57, 1.00] and mostly engaged

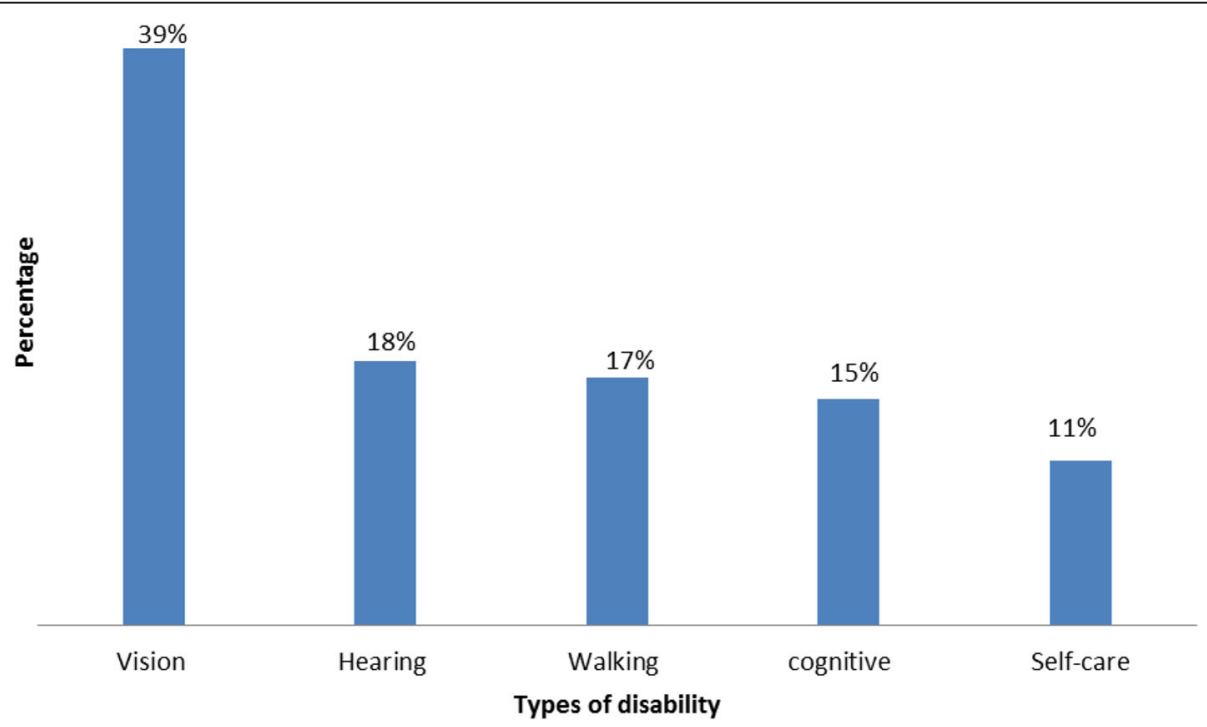

Fig. 1 Number of individuals who reported disability among population of Dabat HDSS, northwest Ethiopia. October-December 2014 ( $N=1228$ ) 
Table 3 Types of disability by age and gender at Dabat HDSS, October-December $2014(\mathrm{~N}=67,395)$

\begin{tabular}{|c|c|c|c|c|c|c|c|c|c|c|}
\hline \multirow{3}{*}{$\begin{array}{l}\text { Types of } \\
\text { disability } \\
(N=1369)\end{array}$} & \multicolumn{2}{|c|}{ Age $<5$ years } & \multicolumn{2}{|c|}{ Age $5-15$ years } & \multicolumn{2}{|c|}{ Age $15-49$ years } & \multicolumn{2}{|c|}{ Age $\geq 50$ years } & \multicolumn{2}{|l|}{ Total } \\
\hline & $\begin{array}{l}M \\
N=4584\end{array}$ & $\begin{array}{l}F=4503 \\
N=4\end{array}$ & $\begin{array}{l}M \\
N=9876\end{array}$ & $\begin{array}{l}F \\
N=9985\end{array}$ & $\begin{array}{l}M \\
N=14,601\end{array}$ & $\begin{array}{l}F \\
N=15,206\end{array}$ & $\begin{array}{l}M \\
N=4109\end{array}$ & $\begin{array}{l}F=4521 \\
N=1\end{array}$ & $\begin{array}{l}\mathrm{M} \\
N=33,181\end{array}$ & $\begin{array}{l}F \\
N=34,214\end{array}$ \\
\hline & n (\%) & & & & & & & & & \\
\hline $\begin{array}{l}\text { Cognitive } \\
N=208\end{array}$ & $1(0.02)$ & $2(0.04)$ & $10(0.10)$ & $10(0.10)$ & $57(0.39)$ & $79(0.52)$ & $18(0.44)$ & $31(0.69)$ & $86(0.26)$ & $122(0.36)$ \\
\hline $\begin{array}{l}\text { Vision } \\
N=534\end{array}$ & $3(0.07)$ & $0(0.00)$ & $16(0.16)$ & $21(0.21)$ & $56(0.38)$ & $94(0.62)$ & $143(3.48)$ & $201(4.45)$ & $218(0.66)$ & $316(0.92)$ \\
\hline $\begin{array}{l}\text { Hearing } \\
N=244\end{array}$ & $2(0.04)$ & $0(0.00)$ & $15(0.15)$ & $13(0.13)$ & $52(0.36)$ & $67(0.44)$ & $41(1.00)$ & $54(1.2)$ & $110(0.33)$ & $134(0.39)$ \\
\hline $\begin{array}{l}\text { Walking } \\
N=230\end{array}$ & $3(0.07)$ & $4(0.1)$ & $20(0.2)$ & $6(0.06)$ & $51(0.35)$ & $50(0.33)$ & $51(1.24)$ & $45(1)$ & $125(0.38)$ & $105(0.31)$ \\
\hline $\begin{array}{l}\text { Self-care } \\
N=153\end{array}$ & $3(0.07)$ & $4(0.09)$ & $11(0.11)$ & $9(0.09)$ & $30(0.21)$ & $33(0.22)$ & $36(0.88)$ & $27(0.6)$ & $80(0.24)$ & $73(0.21)$ \\
\hline
\end{tabular}

in work-related physical activities [AOR: 0.36; 95\% CI: $0.27,0.49$ ] were found with lower odds of getting a disability (Table 4).

\section{Discussion}

This study is one of the largest studies conducted to document key health events in Ethiopia. The overall prevalence of disability was $1.82 \%$. This burden corresponds to $7.6 \%$ of households reporting at least one person with disability.

Our finding is in line with the study done in Ghana, $1.8 \%$ [17]. This prevalence was lower than that of a previous study done in northern Ethiopia, which was $4.9 \%$ [18]. However, it was higher than the prevalence reported from other developing countries, such as Bahrain $0.4 \%$ [19] and Nepal 1\% [20]. The observed discrepancy could be attributed to variations in the measurement of disability, methods utilized [21], and the primary goals of the surveys [22]. The burden of disability in our study corresponds to $7.6 \%$ of households reporting at least one person with disability. This figure is lower than what was reported by a national disability survey conducted in Zimbabwe, where $26 \%$ of households reported at least one member with disability [23].

In this study, vision disability accounts for 534 (39\%) of the total disability burden. This finding is consistent with what was reported by other African countries: Nigeria 37\% [9], South Africa, 32\%) [24], and Zimbabwe (26\%) [23]. This could be explained by poor eye hygiene, a level of access to health care, and health seeking behaviors in most developing countries, in Africa.

Out of the total reported disability, the proportion of hearing disability was $21 \%$. This finding was comparable to that of the study done in South Africa, which was $20 \%$ [25], whereas it was $15 \%$ in Nigeria [9] and $12 \%$ in Zimbabwe [23]. The commonest causes of hearing disabilities in low and middle-income countries are infections from meningitis, measles, maternal rubella, febrile illnesses, and genetic traits [11]. In addition, another study claimed that increasing age was associated with hearing disability [26].

In our study, increasing age was significantly associated with disability. Similar to our finding, a previous study demonstrated that there was a strong association between older age and disability [22]. This is due to the presence of co-morbidities, chronic illnesses, and injuries. Similarly, a study in India indicates that comorbidities, such as non-communicable diseases, increase with aging, which heightened the risk of developing disability [27]. A census of South Africa also showed that the prevalence of disability increased with age, the lowest $(0.2 \%)$ was observed in the age group of $0-9$ years, while the highest (27\%) was among those aged 80 years and above [20, 24].

Household wealth status was inversely associated with disability. The result was supported by previous reports elsewhere $[18,25]$. In fact, poor living conditions, unsafe working environments, poor nutrition, lack of access to clean water, basic sanitation, health care and education [28] are all linked to low socioeconomic status which further predisposes to the risk of developing a disability. A survey from 49 countries also indicated that disability was more prevalent in poorer than in the richest wealth quintiles [1]. Similarly, one of the local studies in Ethiopia showed that the prevalence of adult disability falls as wealth increases [1]. It was also reported that severe household food insecurity was associated with higher odds of getting a disability, which was supported by other findings $[18,26]$. Access to nutrition for poor people is a serious problem in Ethiopia [29]. Evidence showed that access to good nutrition is directly related to food security, which has its own implications on the incidence of disability [22].

In this study, separated marital status increased the odds of having a disability. According to a study in the Netherlands on the population of 18,973 aged 15-74, 
Table 4 Factors associated with disability among people at Dabat HDSS site, northwest Ethiopia, 2014

\begin{tabular}{|c|c|c|c|c|}
\hline Variables & Disability yes n(\%) & COR $(95 \% \mathrm{Cl})$ & AOR $(95 \% \mathrm{Cl})$ & Over all p-value \\
\hline \multicolumn{5}{|l|}{ Sex } \\
\hline Female & $679(1.98)$ & & 1 & 0.001 \\
\hline Male & $547(1.65)$ & $0.82(0.74,0.93)$ & $0.98(0.75,1.28)$ & \\
\hline \multicolumn{5}{|l|}{ Age in year } \\
\hline$\leq 14$ & $137(0.47)$ & 1.00 & & $<0.001$ \\
\hline 15 to 49 & $517(1.73)$ & $3.71(3.03,4.48)$ & $1.57(0.70,3.53)$ & \\
\hline$\geq 50$ & $572(6.63)$ & $14.9(12.37,18.1)$ & $4.49(1.95,10.33)$ & \\
\hline Wealth status & & & & $<0.001$ \\
\hline Poorest quintile & $314(3.31)$ & 1 & & \\
\hline Second quintile & $256(2.26)$ & $67.4(0.56,0.79)$ & $0.76(0.57,1.00)$ & \\
\hline Third quintile & $201(1.54)$ & $0.45(0.38,0.54)$ & $0.75(0.56,0.99)$ & \\
\hline Fourth quintile & $238(1.63)$ & $0.48(0.40,0.57)$ & $0.67(0.51,0.89)$ & \\
\hline Richest quintile & $195(1.18)$ & $0.34(0.29,0.42)$ & $0.55(0.41,0.75)$ & \\
\hline Residence & & & & $>0.05$ \\
\hline Rural & 909 (1.79) & 1 & & \\
\hline Urban & $319(1.89)$ & $1.06(0.93,1.21)$ & $0.99(0.76,1.30)$ & \\
\hline Educational status & & & & $<0.001$ \\
\hline Illiterate & $44(0.32)$ & 1 & & \\
\hline Can read \& write & $823(3.89)$ & $12.5(9.25,16.9)$ & $0.85(0.16,4.51)$ & \\
\hline Primary school & $110(1.99)$ & $627(4.41,8.91)$ & $0.6(0.11,3.19)$ & \\
\hline High school & $87(0.79)$ & $2.48(1.72,3.56)$ & $0.6(0.11,3.18)$ & \\
\hline Diploma and above & $162(1.01)$ & $3.15(2.26,4.40)$ & $0.3(0.06,1.63)$ & \\
\hline \multicolumn{5}{|l|}{ Occupation } \\
\hline Under age & $114(0.56)$ & 1 & & \\
\hline Student & $120(0.86)$ & $1.54(1.19,1.99)$ & $0.50(0.29,0.87)$ & $<0.001$ \\
\hline Farmer & $277(2.19)$ & $3.99(3.20,4.97)$ & $0.47(0.30,0.74)$ & $<0.001$ \\
\hline All type of paid job & $81(1.71)$ & $3.10(2.33,4.14)$ & $0.46(0.28,0.77)$ & $<0.001$ \\
\hline Unemployed & $17(1.61)$ & $2.92(1.74,4.87)$ & $0.66(0.32,1.33)$ & $<0.001$ \\
\hline Other & 55 (16.72) & $35(25.39,50.4)$ & $1.25(0.74,2.11)$ & $<0.001$ \\
\hline Doing work related phy & & & & $<0.001$ \\
\hline Never & $400(8.89)$ & 1 & & \\
\hline Sometimes & $375(2.28)$ & $0.24(0.21,0.27)$ & $0.59(0.46,0.77)$ & \\
\hline Most of the time & $275(1.61)$ & $0.17(0.14,0.19)$ & $0.36(0.27,0.49)$ & \\
\hline \multicolumn{5}{|l|}{ Food security } \\
\hline Secure & $427(1.33)$ & 1 & & \\
\hline Mildly insecure & $115(1.58)$ & $1.18(0.96,1.46)$ & $1.18(0.86,1.62)$ & 0.105 \\
\hline Moderately insecure & $430(2.26)$ & $1.71(1.49,1.96)$ & $1.49(1.20,1.86)$ & $<0.01$ \\
\hline Severely insecure & $202(3.52)$ & $2.69(2.28,3.19)$ & $2.11(1.59,2.80)$ & $<0.01$ \\
\hline \multicolumn{5}{|l|}{ Location of place } \\
\hline High land & $830(1.84)$ & 1 & & \\
\hline Low land & $396(1.77)$ & $0.96(0.85,1.08)$ & $0.93(0.75,1.15)$ & 0.520 \\
\hline \multicolumn{5}{|l|}{ Marital status } \\
\hline Under age & $79(0.39)$ & 1 & & \\
\hline Married & $460(2.11)$ & $5.45(4.29,6.93)$ & $4.07(0.67,24.51)$ & $<0.001$ \\
\hline Single & $312(1.58)$ & $4.07(3.17,5.21)$ & $5.25(0.87,31.51)$ & $<0.001$ \\
\hline Divorced & $143(5.98)$ & $16(12.20,21.3)$ & $5.47(0.90,33.31)$ & $<0.001$ \\
\hline Widowed & $205(8.69)$ & $23.9(18.4,31.2)$ & $4.03(0.66,24.70)$ & $<0.001$ \\
\hline Separated & $27(2.74)$ & $7(4.58,11.1)$ & $7.52(1.18,47.84)$ & $<0.001$ \\
\hline
\end{tabular}


married people were found with lesser odds of disability compared to their unmarried counterparts, single, divorced, or widowed [30]. Another study done in middle and low-income countries also showed that the prevalence was higher among divorced/separated/widowed adults than among the married/cohabiting respondents [2]. A disability doesn't affect only individual health but also brings family/social crisis in a marriage. A previous study indicated that parents with a child on the Autistic Spectrum got divorced [31].

This is one of the biggest studies investigating the burden of disability in northwest Ethiopia and is believed to fill the knowledge gap and contribute to policy determination, clinical practice, and decision-making in the country. However, it is not free from some limitations. For instance, the study did not show the severity as well as the definitive causes of disability due to the crosssectional nature of the study. In addition, the selfreported nature of this study means that the problems can be under or over reported. Disability is an umbrella term and the problems associated with it were not studied in depth. For example, the magnitude of limitations in each and every activity of daily living was not assessed.

\section{Conclusion}

Even though the prevalence of disability in our finding is lower than the global statistics, the study reveals that there is a noticeable burden of disability at the Dabat HDSS site. Vision disability is the highest of all disabilities. Age, wealth status, food security status, marital, and occupational status were significantly associated with disability. Community education and creating a safe environment are key to prevent injuries which can result in disabilities. There is also a need to establish social protection strategies for the older, food in-secured, and poorest segments of the community. Furthermore, future researches need to cover a wider range and depth of disability to properly quantify disability and problems associated with it.

\section{Abbreviations \\ ADL: Activities of daily livings; AOR: Adjusted odds ratio; HDSS: Health and demographic surveillance system; HFIAS: Household Food Insecurity Access Scale; HRS: Household Registration System; INDEPTH: International Network of Demographic Evaluation of Populations and Their Health; LFS AHM: Labour Force Survey ad hoc module; PCA: Principal Component Analysis; SADPD: Secretariat for the African decade of disabled person}

\section{Acknowledgements}

Authors would like to thank the Dabat population and all respondents for their willingness to participate in the study. They are also grateful to the University of Gondar, Ethiopian Public Health Association/CDC for funding and material support. Finally, authors' appreciations go to Dabat HDSS site staffs for their unreserved contribution in data collection activities.

\section{Authors' contribution}

$M^{*} C^{*}, S M, G A, Y K, M Y, K A, T A, M W, A G$ designed the study, developed the tool, coordinated the data collection activity. MB* ${ }^{*}, S M, G A, T A, A S, A T, Z G$ carried out the statistical analysis. EG participated in the design of the study, tool development, and drafting the manuscript. MB* SM AT, GA drafted the manuscript. All authors read and approved the final manuscript.

\section{Funding}

This study was funded by Ethiopian Public Health Association/CDC and the University of Gondar. The views presented in the article are of the author and not necessarily express the views of the funding organization. The funders were not involved in the design of the study, data collection, analysis and interpretation.

\section{Availability of data and materials}

Data will be available upon request from the corresponding author.

\section{Ethics approval and consent to participate}

The study protocol was ethically approved by the Ethical Review Board (IRB) of the University of Gondar. Written informed consent was obtained from the head of the household. Moreover, the confidentiality of information was guaranteed by using code numbers rather than personal identifiers and by keeping the data locked.

\section{Consent for publication}

Not applicable.

\section{Competing interests}

The authors declare that they have no competing interests.

\section{Publisher's Note}

Springer Nature remains neutral with regard to jurisdictional claims in published maps and institutional affiliations.

\section{Author details}

'Department of Physiotherapy, School of Medicine, College of Medicine and Health Science, University of Gondar, P.o. Box 196, Gondar, Ethiopia. ${ }^{2}$ Department of Human Nutrition, Institute of Public Health, College of Medicine and Health Sciences, University of Gondar, Gondar, Ethiopia. ${ }^{3}$ Department of Health Service Management and Health Economics, Institute of Public Health College of Medicine, University of Gondar, Gondar, Ethiopia. ${ }^{4}$ Department of Epidemiology and Biostatistics, Institute of Public Health College of Medicine and Health Science, University of Gondar, Gondar, Ethiopia. ${ }^{5}$ Department of Environmental and Occupational Health and Safety, Institute of Public Health College of Medicine and Health Science, University of Gondar, Gondar, Ethiopia. ${ }^{6}$ Dabat Research Centre Health and Demographic Surveillance System, Institute of Public Health College of Medicine and Health Science, University of Gondar, Gondar, Ethiopia. ${ }^{7}$ Department of Reproductive Health, Institute of Public Health, College of Medicine and Health Science, University of Gondar, Gondar, Ethiopia.

Received: 1 November 2016 Accepted: 15 September 2017 Published online: 02 October 2017

References

1. Hosseinpoor AR, Williams JAS, Gautam J, Posarac A, Officer A, Verdes E, et al. Socioeconomic inequality in disability among adults: a multicountry study using the world health survey. Am J Public Health. 2013;103:1278-86.

2. Hosseinpoor AR, Bergen N, Kostanjsek N, Kowal P, Officer A, Chatterji S. Socio-demographic patterns of disability among older adult populations of low-income and middle-income countries: results from World Health Survey. Int J Public Health Springer Basel. 2015;61:337-45.

3. WHO. World report on disability 2011. www.who.int/disabilities/world_ report/2011/report.pdf

4. Dawson VL, Balloch S, Moore AP. Rehabilitation services for persons affected by stroke in Jordan. Disabil Incl Dev. 2011;22:73-84.

5. Mitra S, Posarac A, Vick B. Disability and poverty in developing countries: A snapshot from the world health survey. 2011;1109. Available at http://dx.doi. org/10.2139/ssrn.1908128.

6. Schulze M. Understanding The UN Convention On The Rights Of Persons With Disabilities. Advocate. 2010;1:1-4. 
7. Federal Democratic Republic of Ethiopia Ministry of Labour and Social Affairs (MOLSA). Baseline study on the status of persons with disabilities and the influence of the African decade pronouncement in Ethiopia. Policy and Implimentation. 2010.

8. Wandera SO, Ntozi J, Kwagala B. Prevalence and correlates of disability among older Ugandans: evidence from the Uganda National Household Survey. Glob Health Action. 2014;7:1, 25686. doi:10.3402/gha.v7.25686.

9. Smith N. The face of disability in Nigeria: a disability survey in Kogi and Niger States. Disability, CBR and Inclusive Development. 2011;22:1. doi:10.5463/DCID.v22i1.11.

10. Madans JH, Loeb ME, Altman BM. Measuring disability and monitoring the UN Convention on the rights of persons with disabilities: the work of the Washington Group on Disability Statistics. BMC Public Health [Internet] BioMed Central Ltd. 2011;11(Suppl 4):S4. https://doi.org/10.1186/1471-245811-S4-S4.

11. Maulik PK, Darmstadt GL. Childhood disability in low-and-middle-income countries: overview of screening, prevention, services, legislation, and epidemiology. Pediatrics. 2007;120(Supplement 1):S1-55. doi:10.1542/peds. 2007-0043B.

12. Mengesha ZB, Biks GA, Ayele TA, Tessema GA. Determinants of skilled attendance for delivery in Northwest Ethiopia: a community based nested case control study. BMC Public Health. 2013;13:130. https://doi.org/10.1186/ 1471-2458-13-130.

13. Eurostat. Employment of Disabled People: Statistical analysis of the 2011 Labour Force Survey ad hoc module. 2015;148. Available from http://ec. europa.eu/eurostat/documents/3888793/6802087/KS-TC-14-007-EN-N.pdf/ 5c364add-6670-4ac9-87c7-9b8838473a7b.

14. Coates J, Bilinsky P, Coates J. Household Food Insecurity Access Scale (HFIAS) for Measurement of Food Access: Indicator Guide VERSION 3 Household Food Insecurity Access Scale (HFIAS) for Measurement of Food Access: Indicator Guide VERSION 3. 2007.

15. Gebreyesus SH, Lunde T, Mariam DH, Woldehanna T, Lindtjørn B. Is the adapted Household Food Insecurity Access Scale (HFIAS) developed internationally to measure food insecurity valid in urban and rural households of Ethiopia? BMC Nutrition. 2015;1(1):2. https://doi.org/10.1186/ 2055-0928-1-2.

16. Abebe Z, Gebeye E, Tariku A. Poor dietary diversity, wealth status and use of un-iodized salt are associated with goiter among school children: a crosssectional study in Ethiopia. BMC Public Health [Internet] BMC Public Health. 2017:1-11. Available from: doi: 10.1186/s12889-016-3914-z.

17. Biritwum RB, Devres JP, Ofosu-Amaah S, Marfo C, Essah ER. Prevalence of children with disabilities in central region, Ghana. West Afr J Med. 2001;20:249-55

18. Tamrat G, Kebede Y, Alemu S, Moore J. The prevalence and characteristics of physical and sensory disabilities in Northern Ethiopia. Disabil Rehabil. 2001;23:799-804.

19. Al-Ansari A. Prevalence estimates of physical disability in Bahrain-a household survey. Int Disabil Stud. 1989;11:21-24. http://dx.doi.org/10.3109/ 02599148909166372

20. Sauvey S, Osrin D, Manandhar DS, Costello AM, Wirz S. Prevalence of childhood and adolescent disabilities in rural Nepal. Indian Pediatr. 2005;42:697-702.

21. Loeb ME, Eide AH, Mont D. Approaching the measurement of disability prevalence: the case of Zambia. Alternatives. 2008;2:32-43.

22. Williams JS, Kowal $P$, Hestekin $H, O^{\prime}$ Driscoll $T$, Peltzer $K$, Yawson A, Biritwum R, Maximova T, Rodríguez AS, Espinoza BM, Wu F. Prevalence, risk factors and disability associated with fall-related injury in older adults in low-andmiddle-income countries: results from the WHO Study on global AGEing and adult health (SAGE). BMC medicine. 2015;13(1):147. doi:10.1186/s12916015-0390-8.

23. Ministry of Health and Child Care Zimbabwe \& UNICEF. Living Conditions Among Persons with Disability Survey. Key Finding Report 2013. Accessible at https://www.unicef.org/zimbabwe/National_Survey_on_Disability_ 2013(1).pdf.

24. Pali Lehohla. Prevalence of disability in South Africa. Census 2001 [Internet]. Pretoria, South Africa: Statistics South Africa, Private Bag X44, Pretoria 0001 (c) Statistics South Africa, 2005 Users; 2005. Available from: http://www. statssa.gov.za/census/census_2001/disability/Disability.pdf.

25. Couper J. Disability in rural Kwazulu. S Afr Med J. 2002;92:549-52. July 2002

26. Schneider J. Hearing loss impacts on the use of community and informal supports. Age Ageing. 2010;39:458-64. June 2010.
27. Basu S, King AC. Original contribution disability and chronic disease among older adults in India: detecting vulnerable populations through the WHO SAGE study. 2013;178:1620-1628. https://doi.org/10.1093/aje/kwt191.

28. Groce N, Bailey N, Lang R, Trani JF, Kett M. Water and sanitation issues for persons with disabilities in low-and-middle-income countries: a literature review and discussion of implications for global health and international development. J Water Health. 2011;9(4):617-27. doi:10.2166/wh.2011.198

29. Central Statistical Agency [Ethiopia]. Ethiopia Mini Demographic and Health Survey 2014. Ethiopia: Addis Ababa; 2014.

30. Joung IMA, Van De Mheen HVD, Stronks K, Van Poppel FWA, Mackenbach JP. Differences in self-reported morbidity by marital status and by living arrangement. Int J Epidemiol. 1994;23:91-7.

31. Sobsey D. Marital stability and marital satisfaction in families of children with disabilities: Chicken or egg? Dev Disabil Bull. 2004;32:62-83.

\section{Submit your next manuscript to BioMed Central and we will help you at every step:}

- We accept pre-submission inquiries

- Our selector tool helps you to find the most relevant journal

- We provide round the clock customer support

- Convenient online submission

- Thorough peer review

- Inclusion in PubMed and all major indexing services

- Maximum visibility for your research

Submit your manuscript at www.biomedcentral.com/submit

) Biomed Central 